\title{
Clinical Risk Factors and Angiographic Pattern of Coronary Artery Disease in Young Females
}

\author{
Hadi Yousuf Saeed ${ }^{1}$, Fawad Qadir ${ }^{1}$, Muhammad Shahid ${ }^{1}$, Muhammad Tahir Mohyudin ${ }^{2}$, Abu Bakar Ali \\ Saad $^{3}$, Zahid Iqbal ${ }^{4}$ \\ ${ }^{1}$ Senior Registrar, Department of Cardiology, CPE Institute of Cardiology, Multan \\ ${ }^{2}$ Associate Professor, Department of Cardiology, CPE Institute of Cardiology, Multan \\ ${ }^{3}$ Assistant Professor, Department of Cardiology, CPE Institute of Cardiology, Multan \\ ${ }^{4}$ Senior Registrar, Department of Cardiology, DG Khan Medical College/Hospital, DG Khan
}

\begin{abstract}
AB S TRACT
Background: Coronary artery disease (CAD) is associated with the highest mortality in women around the world. The objective of this study was to compare the clinical risk factors and angiographic pattern of coronary artery disease in young versus old age females having CAD.

Material and Methods: This cross-sectional study was conducted at the Department of Cardiology, Chaudhry Pervaiz Elahi (CPE) Institute of Cardiology Multan, Pakistan from April 2018 to December 2018. All females with diagnosis of angina and consistent ischemic changes on ECG were enrolled in the study. A total of 230 females were included with 123 patients aged $\leq 45$ years and 107 patients aged $>45$ years. Comparison of patient characteristics, clinical risk factors and angiographic pattern in young and old age females was done by using SPSS version 21 statistical software. Results: Prevalence of hypertension $(P=0.001)$, dyslipidemia $(P=0.06)$ and diabetes mellitus $(P=0.007)$ was significantly higher in females of older age group (>45 years). Similarly, a larger number of older age females $(32 ; 29.9 \%)$ presented with ST-Elevation Myocardial Infarction (STEMI) as compared to young female patients $(22 ; 17.88 \%)(P=0.03)$. Regarding angiographic patterns of CAD, there was no difference in the prevalence of single vessel disease (SVD), double vessel disease (DVD) and triple vessel disease (TVD) between the groups. Normal angiogram was found in 13 $(12.3 \%)$ old age females versus $35(28.8 \%)$ young females, respectively $(P=0.002)$.

Conclusions: The risk factors profile and clinical presentation of CAD is different in young female patients with CAD. There is an essential need to determine the coronary atherosclerosis factors in young females and these women should be treated more aggressively to prevent adverse cardio-vascular outcomes.

Key words: Angiographic Pattern, Coronary Artery Disease, Clinical Pattern, Young Females

Authors' Contribution:

1-3 Conception; Literature research;

manuscript design and drafting; ${ }^{4-6}$ Critical

analysis and manuscript review; Data analysis; Manuscript Editing.

Cite this article. Saeed HY, Qadir F, Shahid M, Mohyudin MT, Saad AA, Iqbal Z. Clinical Risk Factors and Angiographic Pattern of Coronary Artery Disease in Young Females. J Islamabad Med Dental Coll.2020; 9(1): 17-22. Doi: 10.35787/jimdc.v9i1.377

Correspondence:

Hadi Yousuf Saeed

Email:doc.cpeic@gmail.com

Article info:

Received: July 14, 2019

Accepted: March 16, 2020

\section{Introduction}

Coronary artery disease (CAD) is associated with the highest mortality in women around the world. At present, in USA one out of every three women dies of CAD, accounting to about $50 \%$ of deaths due

to any cause. ${ }^{1}$ South Asia including Pakistan has the highest prevalence of CAD, ranging from more than $50 \%$ to $300 \%$ than the rest of the world. ${ }^{2}$ In Pakistan, nearly $30 \%$ females of age $>45$ years are
\end{abstract}


affected by CAD in contrast to only $23.7 \%$ males. $^{3} \mathrm{~A}$ study conducted in Karachi reported that from 1970 the prevalence of CAD in urban community has doubled to this time. ${ }^{4}$

CAD mostly affects men and usually it affects the women after menopause. ${ }^{5}$ Recent studies have reported a prominent increase in mortality in premenopausal women due to CAD. ${ }^{5}$ It is still unclear how the menopause effects CAD. Moreover, due to lower prevalence of CAD in young females, they are not properly educated about preventive factors of CAD. ${ }^{6}$ Due to low awareness regarding cardiovascular diseases in younger age group, they remain under-diagnosed and untreated in many of the patients. In a study conducted by Dave et al among rural Indian females undergoing coronary angiography (CAG), there was a higher proportion of triple vessel disease (39.6\%) than double vessel disease (12.9\%) or single vessel disease (15.8\%), with normal coronaries in only $30.7 \%$ female patients. ${ }^{7}$

This study aimed to compare the clinical presentation and angiographic pattern of coronary artery disease among young females aged $\leq 45$ years and older females aged $>45$ years.

\section{Material and Methods}

This cross-sectional study was conducted at the Department of Cardiology, CPE Institute of Cardiology Multan, Pakistan. It was conducted ove $r$ a period of eight months, from April 2018 to December 2018. All females complaining of angina with a positive stress test or consistent ischemic changes in ECG (such as consistent ST elevation or significant ST depression) were included in the study. Female patients with valvular heart disease, congenital heart disease (CHD), pregnancy and renal failure were excluded. A cut-off value of 45 years of age was used ( $\leq 45$ years - young females versus $>45$ years - older females). Sample size for this study was calculated by taking estimated prevalence of CAD in female patients as $69.3 \%^{7}$ who underwent CAG and level of significance at $6.0 \%$. The calculated sample size was 228 patients and was rounded off to 230 patients.

All patients were followed till they underwent coronary angiography. Elective coronary angiogram (CAG) was performed through femoral artery or radial approach. Interpretation of CAG report was performed by senior cardiologists. CAD was defined as stenosis of $>50 \%$ in epicardial coronary segment in more than one major coronary artery, while $<50 \%$ was considered as non-significant stenosis. They were into classified into single vessel disease (SVD), double vessel disease (DVD) and triple vessel disease (TVD) depending on the significant stenosis of the major coronary artery. More than 50\% stenosis in left main coronary artery was considered as left main disease (LMD).

Comparison of clinical and angiographic pattern in young and old age females was performed by using SPSS version 21 statistical software using chi-square and independent sample t-test with $P$-value of $<0.05$ considered as statistically significant.

Results

A total of 230 females (mean age $49.3 \pm 6.8$ years) underwent coronary angiography in the cardiac catheterization (cath) lab. The baseline characteristics and risk profile are shown in Table I. There were 123 female patients aged $\leq 45$ years (mean age $40.4 \pm 4.3$ years) and 107 patients aged $>45$ years (mean age $56.3 \pm 5.2$ years) $(P<0.0001)$. Frequency of hypertension ( $P=0.001)$, dyslipid e mia $(P=0.06)$ and diabetes mellitus $(P=0.007)$ was significantly higher in females of older age group (>45 years). Prevalence of Non-ST elevation myocardial infarction (NSTEMI) and unstable angina (USA) was similar in both groups while only 22 


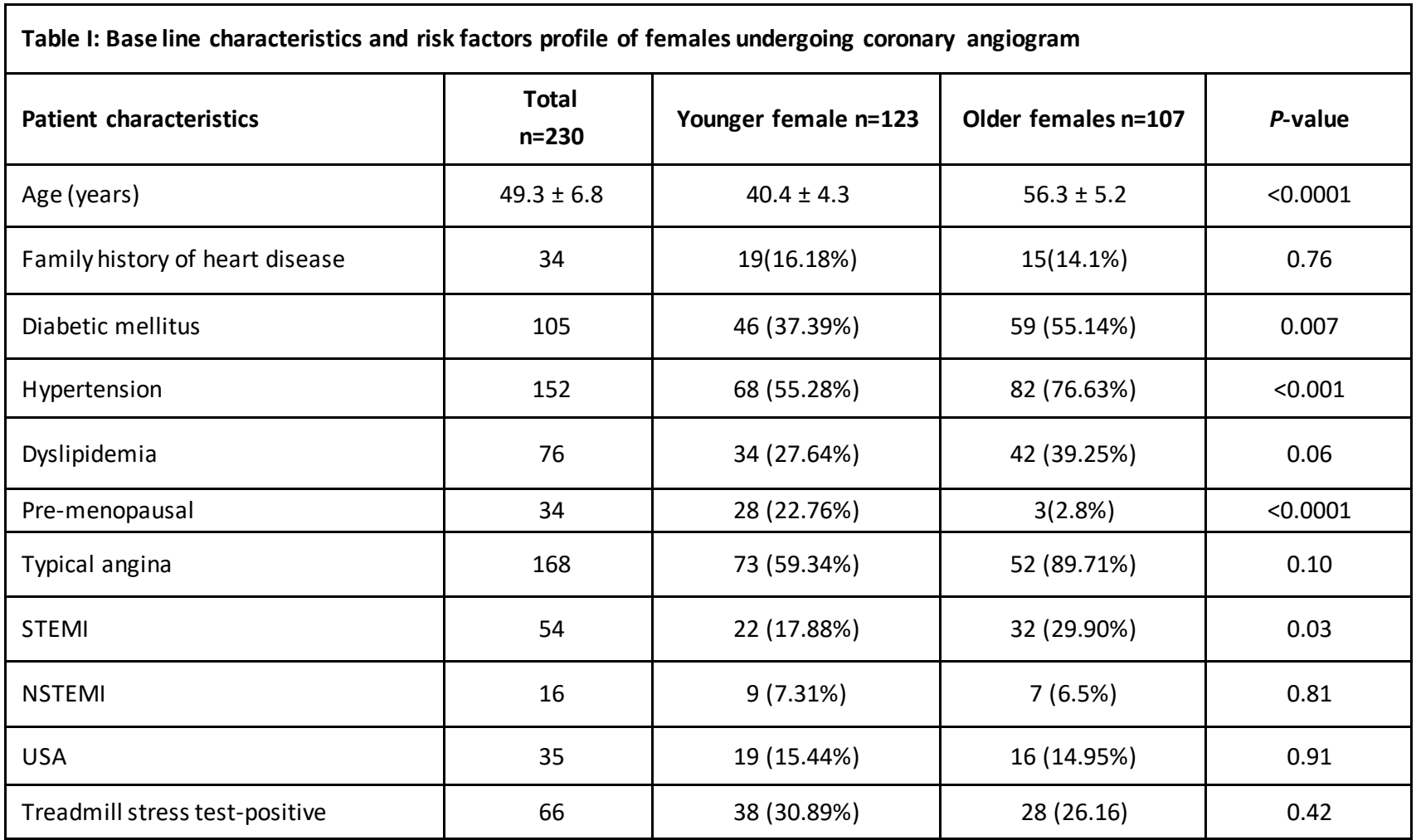

STEMI - ST elevation myocardial infarction; NSTEMI - Non-ST elevation myocardial infarction; USA - unstable angina

\begin{tabular}{|l|c|c|c|c|}
\hline \multicolumn{2}{|l|}{ Table II: Comparison of angiographic pattern of young versus old aged females } \\
\hline Coronary lesions & $\begin{array}{c}\text { Total } \\
\mathbf{n}=\mathbf{2 3 0}\end{array}$ & Younger females $\mathbf{n}=\mathbf{1 2 3}$ & Older females n=107 & $\boldsymbol{P}$-value \\
\hline Left main disease & 4 & $1(0.8 \%)$ & $3(2.8 \%)$ & 0.24 \\
\hline Single vessel disease & 42 & $20(16.2 \%)$ & $22(20.7 \%)$ & 0.39 \\
\hline Double vessel disease & 34 & $14(11.4 \%)$ & $20(18.7 \%)$ & 0.11 \\
\hline Triple vessel disease & 54 & $26(21.4 \%)$ & $28(26.1 \%)$ & 0.36 \\
\hline Non-significant stenosis & 48 & $27(21.4 \%)$ & $21(19.4 \%)$ & 0.66 \\
\hline Normal coronaries & 48 & $35(28.8 \%)$ & $13(12.3 \%)$ & 0.002 \\
\hline
\end{tabular}

(17.88\%) young females and $32(29.90 \%)$ old age females presented with STEMI $(P=0.03)$ (Table I).

Regarding angiographic patterns, SVD was diagnosed in $20(16.2 \%)$ young females as compared to $22(20.7 \%)$ females in the older age group ( $P=0.39$ ). Similarly, there was no difference in the prevalence of DVD and TVD between the two groups. However, normal angiogram was found in only 13 (12.3\%) females in older age group as compared to $35(28.8 \%)$ young females ( $P=0.002)$ (Table II).

\section{Discussion}

This study aimed to compare the clinical presentation and angiographic pattern of coronary artery disease among young females aged $\leq 45$ years and older females aged $>45$ years. Other studies have also used 45 years as a cut off value to 
define young age.$^{8,9}$ However, a study by Christus et al used the cut off value of 35 years to define young age in females. ${ }^{10}$ CAD is a well-established cause of mortality in female population. A multi-country based INTERHEART study involving 52 thousand patients of CAD concluded that although the prevalence of CAD in females is approximately 10 years later as compared to males, mortality is rapidly increasing in the female population. ${ }^{11}$

Global Use of Strategies to Open Occluded Coronary Arteries in Acute Coronary Syndromes (GUSTO IIB) investigators and Thrombolysis in Myocardial Infarction (TIMI IIIB) trial investigators found that women present more frequently with unstable angina and NSTEMI, while men present more frequently with STEMI and reperfusion therapy is more frequent in females than males. ${ }^{12,13}$

Moreover atypical presentation in females with vague and more generalized signs and symptoms make the diagnosis more difficult. ${ }^{14,15}$ Lack of proper knowledge regarding risk factors of CAD and clinical presentation may delay the presentation in women with CAD attack. ${ }^{16}$ Prevalence of CAD in young females is much higher (12-16\%) in Asian countries than the western countries (5\%). ${ }^{17}$

In the present study, there was no significant difference in risk factors of CAD in young females as compared to older ones. We found diabetes mellitus in $37.39 \%$ young females versus $55.14 \%$ old age females, hypertension in $55.28 \%$ in young versus $76.63 \%$ old age females, and dyslipidemia in $27.64 \%$ young females and $39.25 \%$ old age females. Prevalence of family history of heart disease was also similar in both groups.

Similar findings have been reported in other studies. Soman et al. conducted a study on young (aged 30-40 years) and older (aged 41-50 years) females with CAD. They also reported a higher frequency of hypertension (young $20 \%$; old $51.78 \%$ ) and diabetes (young $10 \%$; old $48.21 \%$ ) in older aged females. ${ }^{18}$ Another study by Ezhumalai et al also reported higher prevalence of diabetes and dyslipidemia in old age females as compared to the youngerones. ${ }^{19}$

Kher et al. conducted a comparative study between young male and female patients to study the risk factor profile and type of CAD. The authors found higher prevalence of hypertension and diabetes in young females as compared to the young males. However, incidence of STEMI and NSTEMI was higher in young males as compared to females. ${ }^{20}$

In our study, frequency of NSTEMI and USA was higher in younger females, while incidence of STEMI was higher in older age female patients with CAD. These results are comparable to those reported by Soman et al who also found higher incidence of NSTEMI and USA in young female patients. ${ }^{18}$

We did not find any difference in the incidence of severity of CAD in both young and old age female patients. Ezhumalai et al found higher incidence of DVD (19.7\% versus $15.2 \%)$ and TVD (16.5\% versus $7.8 \%$ ) in old age females as compared to the young age females. ${ }^{19}$

The VIRGO study emphasized on the importance of risk identification, and education of young females at all levels of health care management systems. ${ }^{21}$ Since the risk profile is different in young females, so there is a need to re-evaluate the diagnostic and management options in these patients with early implementation of preventive strategies to prevent the occurrence of CAD in these patients.

\section{Conclusion}

The risk factors profile and clinical presentation of $C A D$ in young female patients is different from older age female patients with CAD. There is an essential need to determine the risk factors for coronary atherosclerosis in young females so that they should be treated more aggressively to 
prevent adverse cardio-vascular outcomes and to improve long term prognosis.

\section{References}

1. Mozaffarian D, Benjamin EJ, Go AS, Arnett DK, Blaha MJ, Cushman $M$, et al. Heart Disease and Stroke Statistics-2016 Update: A Report from the American Heart Association. Circulation. 2016; 133(4): e38360. Doi: 10.1161/CIR.0000000000000350

2. Volgman AS, Palaniappan LS, Aggarwal NT, Gupta M, Khandelwal A, Krishnan AV, et al. Atherosclerotic cardiovascular disease in South Asians in the United States: epidemiology, risk factors, and treatments: a scientific statement from the American Heart Association. Circulation. 2018; 138(1): e1-34. Doi: 10.1161/CIR.0000000000000580

3. Jafar TH, Jafary FH, Jessani S, Chaturvedi N. Heart disease epidemic in Pakistan: women and men at equal risk. American heart journal. 2005; 150(2): 221-6. Doi: 10.1016/j.ahj.2004.09.025

4. Aziz KU, Faruqui A, Patel N, Jaffery H. Prevalence and awareness of cardiovascular disease including life styles in a lower middle class urban community in an Asian country. Pak Heart J. 2012; 41(3-4): 11-20.

5. Gyarfas I, Keltai M, Salim Y. Effect of potentially modifiable risk factors associated with myocardial infarction in 52 countries in a case-control study based on the INTERHEART study. Orv Hetil. 2006; 147(15): 675-86. PMID: 16734179

6. Garcia M, Mulvagh SL, Bairey MCN, Buring JE, Manson JE. Cardiovascular disease in women: clinical perspectives. Circ Res. 2016; 118(8): 1273-93. Doi: 10.1161/CIRCRESAHA

7. Dave TH, Wasir HS, Prabhakaran D, Dev V, Das G, Rajani $M$, et al. Profile of coronary artery disease in Indian women: correlation of clinical, non-invasive and coronary angiographic findings. Indian Heart J. 1991; 43(1): 25-9. PMID: 1894297

8. Konishi H, Miyauchi K, Kasai T, Tsuboi S, Ogita M, Naito $R$, et al. Long-term prognosis and clinical characteristics of young adults $(</=40$ years old $)$ who underwent percutaneous coronary intervention. J Cardiol. 2014; 64(3): 171-4. Doi: 10.1016/j.jjcc.2013.12.005

9. van Loon JE, de Maat MP, Deckers JW, van Domburg RT, Leebeek FW. Prognostic markers in young patients with premature coronary heart disease. Atherosclerosis. 2012; 224(1): 213-7. Doi: 10.1016/j.atherosclerosis.2012.06.067

10. Christus T, Shukkur AM, Rashdan I, Koshy T, Alanbaei $M$, Zubaid $M$, et al. Coronary Artery Disease in Patients Aged 35 or less - A Different Beast? Heart
Views. 2011; 12(1): 7-11. Doi: 10.4103/1995$705 \times .81550$

11. Yusuf $S$, Hawken $S$, Ounpuu $S$, Dans $T$, Avezum A, Lanas $F$, et al. Effect of potentially modifiable risk factors associated with myocardial infarction in 52 countries (the INTERHEART study): case-control study. Lancet. 2004; 364(9438): 937-52. Doi: 10.1016/S0140-6736(04)17018-9

12. Hochman JS, Tamis JE, Thompson TD, Weaver WD, White HD, Van de Werf $F$, et al. Sex, clinical presentation, and outcome in patients with acute coronary syndromes. Global Use of Strategies to Open Occluded Coronary Arteries in Acute Coronary Syndromes Ilb Investigators. N Engl J Med. 1999; 341(4): 226-32. Doi: 10.1056/NEJM199907223410402

13. Hochman JS, McCabe $\mathrm{CH}$, Stone PH, Becker RC, Cannon CP, DeFeo-Fraulini $\mathrm{T}$, et al. Outcome and profile of women and men presenting with acute coronary syndromes: a report from TIMI IIIB. TIMI Investigators. Thrombolysis in Myocardial Infarction. J Am Coll Cardiol. 1997; 30(1): 141-8. Doi: 10.1016/s0735-1097(97)00107-1

14. Rubini Gimenez $M$, Reiter $M$, Twerenbold R, Reichlin $T$, Wildi $K$, Haaf $P$, et al. Sex-specific chest pain characteristics in the early diagnosis of acute myocardial infarction. JAMA Intern Med. 2014; 174(2): 241-9. Doi: 10.1001/jamainternmed.2013.12199

15. Mehta LS, Beckie TM, DeVon HA, Grines CL, Krumholz HM, Johnson MN, Lindley KJ, Vaccarino V, Wang TY, Watson KE, Wenger NK. Acute myocardial infarction in women: a scientific statement from the American Heart Association. Circulation. 2016; 133(9): 916-47 DOI: 10.1161/CIR.0000000000000351.

16. Lichtman JH, Leifheit-Limson EC, Watanabe E, Allen NB, Garavalia B, Garavalia LS, et al. Symptom recognition and healthcare experiences of young women with acute myocardial infarction. Circulation Cardiovascular quality and outcomes. 2015; 8(2-S 1): S31-8. Doi: 10.1161/CIRCOUTCOMES.114.001612

17. Enbergs $A$, Burger $R$, Reinecke $H$, Borggrefe $M$, Breithardt G, Kerber S. Prevalence of coronary artery disease in a general population without suspicion of coronary artery disease: angiographic analysis of subjects aged 40 to 70 years referred for catheter ablation therapy. European heart journal. 2000; 21(1): 45-52. Doi: 10.1161/CIRCOUTCOMES.114.001612

18. Soman B, Rahaman MA, Rajan R, Vijayaraghavan G. Risk factor profile and disease pattern in premenopausal and postmenopausal Indian women presenting with acute coronary syndrome. J Clin 
Prevent Cardiol. 2016; 5(3): 78-83. Doi: 10.4103/2250-3528.191098

19. Ezhumalai B, Jayaraman B. Angiographic prevalence and pattern of coronary artery disease in women. Indian Heart J. 2014; 66(4): 422-6. Doi: 10.1016/j.ihj.2014.05.009

20. Kher M, Sathyanarayan BC. Coronary artery disease in young females: current scenario. Ind J Car Dis
Wom. 2017; 2(03): 39-43. Doi:10.1055/s-00371607040

21. Leifheit-Limson EC, D'Onofrio G, Daneshvar M, Geda $M$, Bueno $H$, Spertus JA, et al. Sex differences in cardiac risk factors, perceived risk, and health care provider discussion of risk and risk modification among young patients with acute myocardial infarction: The VIRGO Study. J Am Coll Cardiol. 2015; 66(18): 1949-57. Doi: 10.1016/j.jacc.2015.08.859 